\title{
MACHINING OF INCONEL 718 USING UNCOATED CUTTING TOOLS WITH DIFFERENT CUTTING EDGE QUALITY
}

\author{
Tomas Baksa, Vaclav Schornik, Pavel Adamek \& Miroslav Zetek
}
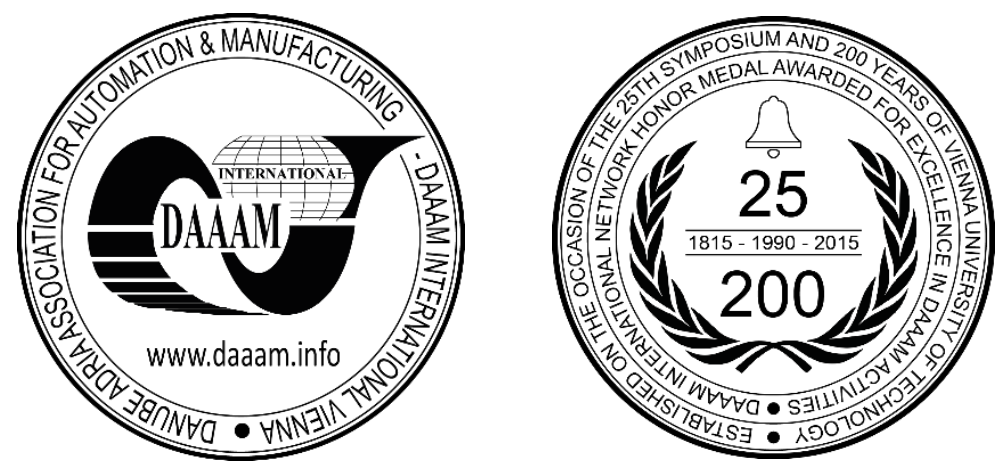

This Publication has to be referred as: Baksa, T[omas]; Schornik, V[aclav]; Adamek, P[avel] \& Zetek, M[iroslav] (2016). Machining of Inconel 718 Using Uncoated Cutting Tools With Different Cutting Edge Quality, Proceedings of the 27th DAAAM International Symposium, pp.0441-0446, B. Katalinic (Ed.), Published by DAAAM International, ISBN 978-3-902734-08-2, ISSN 1726-9679, Vienna, Austria

DOI: $10.2507 / 27$ th.daaam.proceedings.065

\begin{abstract}
This article deals with testing cemented carbide cutting tools during the experimental cutting of Inconel 718 super-alloy. Several carbide end-mills with different cutting edge qualities obtained by different grinding conditions and strategies were used for machining Inconel 718. The main aim is to compare all end-mills in terms of their cutting tool life during cutting. The machining was performed with cutting tools right after grinding without any coating or cutting edge preparation. Cutting forces were measured during machining to find out the influence of the cutting edge quality on the cutting force Fy during the first impact of the tool. Cutting force at the end of the tool life was also measured. The strategy of side milling was used for the cutting tests of tools during machining of Inconel 718. This material is used for highly stressed components in the nuclear industry, such as combustion turbines. The material is very problematic for machining due to its rapid hardening and high heat generation. The influence of the cutting edge after grinding on the cutting process is assessed by means of flank wear and cutting force.
\end{abstract}

Keywords: Cutting edge; Tool life; Inconel 718; Side milling; Cutting force.

\section{Introduction}

Solid carbide cutting tools are of great importance in manufacturing technology. The combination of hard carbide particles and a tough metallic binder creates a perfect cutting material with high wear resistance and fractural toughness. Carbide cutting tools can be used for roughing and finishing operations in the machining of metal alloys. The required geometry of a cutting tool is obtained using the grinding process. The quality of its cutting edge is also affected by grinding. The grinding process and the resulting surface are affected by the grain size of the cemented carbide. It was found that cemented carbides with submicron grain size have a higher surface strength after ultra-precision grinding than carbides with micron grain size. This is due to the higher compressive residual stress of the ground submicron-structured carbides [1]. 
High-strength material such as Inconel 718 is characterized by excellent mechanical properties at high temperatures and is used for heat stressed components in the aerospace, automotive and nuclear industries, and others. However, it is also characterized by its poor machinability. A cutting tool is negatively affected by the high resistance of the material and deformation hardening during the cutting process $[2,3]$. Therefore, it is necessary to develop new cutting tools for effective machining of Inconel 718. Cutting efficiency and cutting tool life are affected by the cutting tool material, geometry, micro-geometry, coating and the cutting process [10].

Machining of Inconel 718 has been the subject of many studies. In [4], the important role played by the cutting temperature was determined during high speed machining of Inconel 718. A comparative study of the influence of the type of coating on tool wear in the micro milling of Inconel 718 is described in [3], where several coating materials were used. The flank wear during the cutting process mostly occurred on the cutting edge. Some local fractures on the cutting edge occurred due to fatigue and built-up edge formation [3]. Uncoated cutting tools can achieve better results at lower cutting speeds than PVD coated tools. This was investigated in [7], where the uncoated tool performed better than coated tools at a cutting speed of $25 \mathrm{~m} / \mathrm{min}$. The chipping resistance of the uncoated tool was increased by the radius on the cutting edge which gave additional mechanical strength. However, increasing the cutting speed up to $50 \mathrm{~m} / \mathrm{min}$ brings worse performance of the uncoated tool than PVD-coated tools. This was due to high wear resistance and the low thermal conductivity of the TiN coating [7]. Influence of different thin layers on the machining of Inconel 718 is described in [9].

Chipping and breakage of the cutting edge are the most common causes of cutting tool failure. It was found that increasing the cutting speed leads to reduction of the cutting force due to softening of the work material. This improves the cutting tool life. However, it depends on the type of milling operation. For example, when the cutting speed is further increased during slot milling, chips are welded on the sides of the slot and this slows the chip flow. On the other hand, cutting speed plays a less important role in side milling, where the chip flow is better [4]. Research [5] shows optimization of the cutting process by changing the cutting edge radius. An appropriate choice of carbide grade with a combination of cutting edge preparation also has an effect on the resulting cutting tool life [2]. The different wear behaviour of up and down milling is described in [6]. It was found that tool flank wear propagation in the up-milling operation was more rapid than for the down-milling operation [6]. The chip formation was also different for up and down milling, where up-milling produced a segmented chip and down-milling produced a discontinuous serrated chip [6].

This paper is focused on the experimental cutting testing of several cutting tools with different cutting edge qualities. The different cutting tool qualities were obtained by different grinding conditions and strategies during the grinding of the primary radial relief. The cutting edges were analysed on an electron microscope after grinding to detect the cutting edge quality. The importance of correct measurement is described in [8], where three measuring methods are suggested. The machining experiment was performed using Inconel 718. Cutting tools were tested without any cutting edge preparation and without coatings in the cutting process of Inconel 718. Flank wear was measured during cutting tests of end-mills on an optical microscope. Cutting forces were measured and analysed during milling of Inconel 718. The influence of the cutting edge quality on the cutting force during the impact was determined.

\section{The experiment and discussion}

Several carbide end-mills were produced using grinding with different grinding conditions. Table 2 shows all the cutting tools and grinding conditions. The same carbide grade was used for all the cutting tools. This carbide grade is produced by standard suppliers and is suitable for the production of precision cutting tools for turning, drilling and milling. The carbide grade is specified in Table 1. Cutting edges were analysed before the cutting test using an electron microscope.

It was found that conditions and the strategy during grinding of the primary radial relief affects the quality of the cutting edge. A high quality cutting edge was achieved using lower feed rates $\mathrm{v}_{\mathrm{fg}}$. A little chipping of the cutting edge occurred when the feed rate increased up to $260 \mathrm{~mm} / \mathrm{min}$, but there was no significant change. However, a significant change occurred when the spin direction of the grinding wheel was changed from $\mathrm{CCW}$ (counter clockwise) to $\mathrm{CW}$ (clockwise). Chipping of the cutting edge occurred even at a low feed rate and it was more significant as the feed rate increased (Fig. 1).

\begin{tabular}{|c|c|c|c|c|c|c|}
\hline Grain size & WC [\%] & Co [\%] & Density [g/cm ${ }^{\mathbf{3}}$ ] & Hardness HRA & Hardness HV30 & TRS [MPa] \\
\hline Sub-micron & 90 & 10 & 14.35 & 91.8 & 1580 & 3800 \\
\hline
\end{tabular}

Table 1. Specification of the carbide grade 


\begin{tabular}{|c|c|c|}
\hline \multirow{2}{*}{ Tool } & \multicolumn{2}{|c|}{ Wheel speed $\mathbf{~}$ cg $=\mathbf{2 0}$ m/s } \\
\cline { 2 - 3 } & $\begin{array}{c}\text { Feed rate } \mathbf{v}_{\mathbf{f g}} \\
{[\mathbf{m m} / \mathbf{m i n}]}\end{array}$ & $\begin{array}{c}\text { Wheel spin } \\
\text { direction }\end{array}$ \\
\hline T1 & 20 & CCW \\
\hline T2 & 50 & CCW \\
\hline T3 & 80 & CCW \\
\hline T4 & 110 & CCW \\
\hline T5 & 140 & CCW \\
\hline T6 & 170 & CCW \\
\hline T7 & 200 & CCW \\
\hline T8 & 230 & CCW \\
\hline T9 & 260 & CCW \\
\hline T10 & 20 & CW \\
\hline T11 & 80 & CW \\
\hline T12 & 170 & CW \\
\hline T13 & 260 & CW \\
\hline
\end{tabular}

Table 2. Cutting tools and grinding conditions

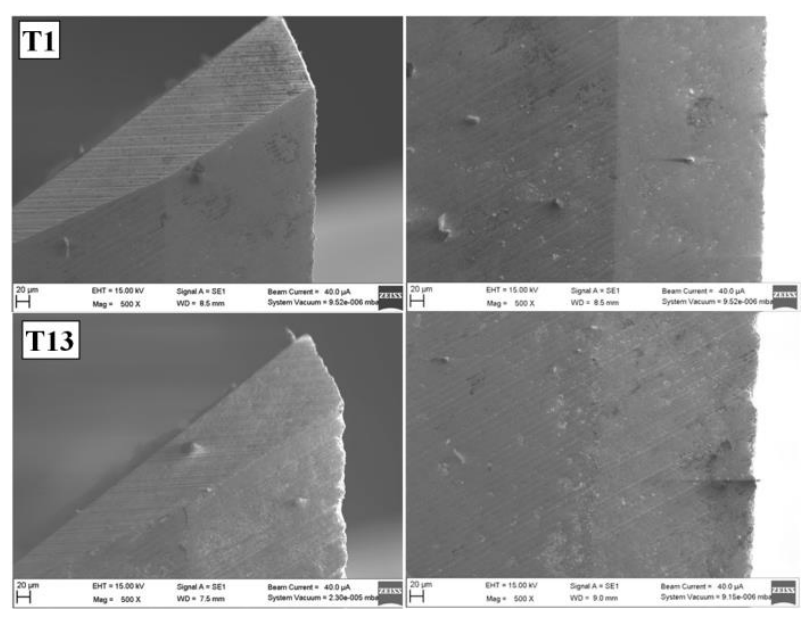

Fig. 1. Cutting edge after grinding

All the milling tools were used in the milling test under constant cutting conditions (Table 3 ). These cutting conditions were determined by previous experiments of cutting Inconel 718 alloy. Because of the high heat generation during the machining of Inconel 718, external coolant was used. Cutting tools were used right after grinding, so there was no edge preparation or coating of the tools. The aim of the experiment was to determine the influence of the cutting edge quality obtained by grinding on cutting tool life. Machining was carried out on Inconel 718 which was clamped onto a KISTLER 9225A dynamometer.

The strategy of side milling was used for the milling test. Down milling was used to increase the stability of the cutting process. Cutting forces were measured during the milling process at the beginning and at the end of the cutting tool life of each tool. The machining strategy and the directions of the components of the cutting forces are shown in Fig. 2a). The cutting tool life was determined based on the critical flank wear VBcrit on the cutting edge. The flank wear was measured on each cutting edge of each tool and the critical value of the flank wear VBcrit was set to $150 \mu$ m. A Multicheck PC500 optical microscope was used for measurements. The measurement site was $2 \mathrm{~mm}$ from the cutting tool face as seen in Fig. 2b).

\begin{tabular}{|c|c|c|c|c|}
\hline $\begin{array}{c}\text { Cutting speed vc } \\
{[\mathbf{m} / \mathbf{m i n}]}\end{array}$ & $\begin{array}{c}\text { Feed speed vf } \\
{[\mathbf{m m} / \mathbf{m i n}]}\end{array}$ & $\begin{array}{c}\text { Axial depth of cut } \\
\text { ap }[\mathbf{m m}]\end{array}$ & $\begin{array}{c}\text { Radial depth of cut } \\
\text { ae }[\mathbf{m m}]\end{array}$ & $\begin{array}{c}\text { Cutting } \\
\text { environment }\end{array}$ \\
\hline 35 & 111 & 3 & 0.5 & External cooling \\
\hline
\end{tabular}

Table 3. Cutting conditions

a)

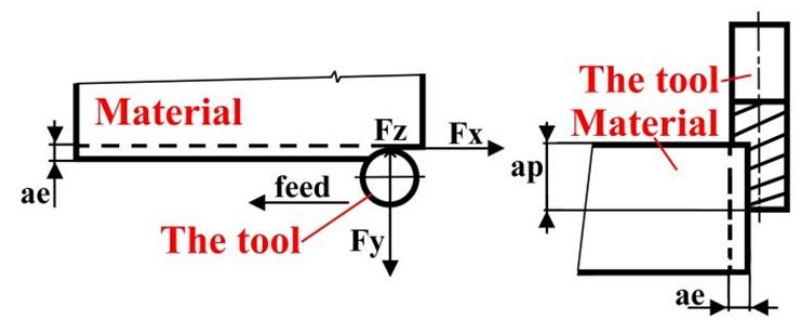

b)

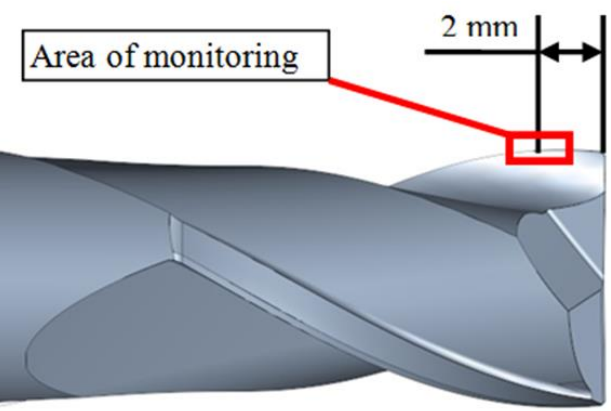

Fig. 2. Cutting strategy (a) and measurement area (b)

In Fig. 4 the results of the cutting test in terms of the cutting tool life are shown. It can be seen that cutting tools ground using CCW strategy T2, T8 and T9 achieve the best results with a durability of $11.7 \mathrm{~min}$. The same durability was achieved by tool T13 which was ground using the CW strategy. The lowest tool life was reached by tools T5 (CCW strategy), T10 and T11 (CW strategy) with a durability of $9.1 \mathrm{~min}$. It seems that the difference in cutting tool life is not significant for tools which were ground at feed rates ranging from 20 to $200 \mathrm{~mm} / \mathrm{min}$. However, increasing the grinding feed rate to above $200 \mathrm{~mm} / \mathrm{min}$ shows better results than at lower grinding feed rates. The strategy of the clockwise grinding (CW) of radial relief at lower feed rate (20 to $80 \mathrm{~mm} / \mathrm{min}$ ) achieved a worse tool life in the cutting test. As in the case of CCW grinding, it seems that the durability of tools ground by the $\mathrm{CW}$ strategy increases with grinding feed rate. 


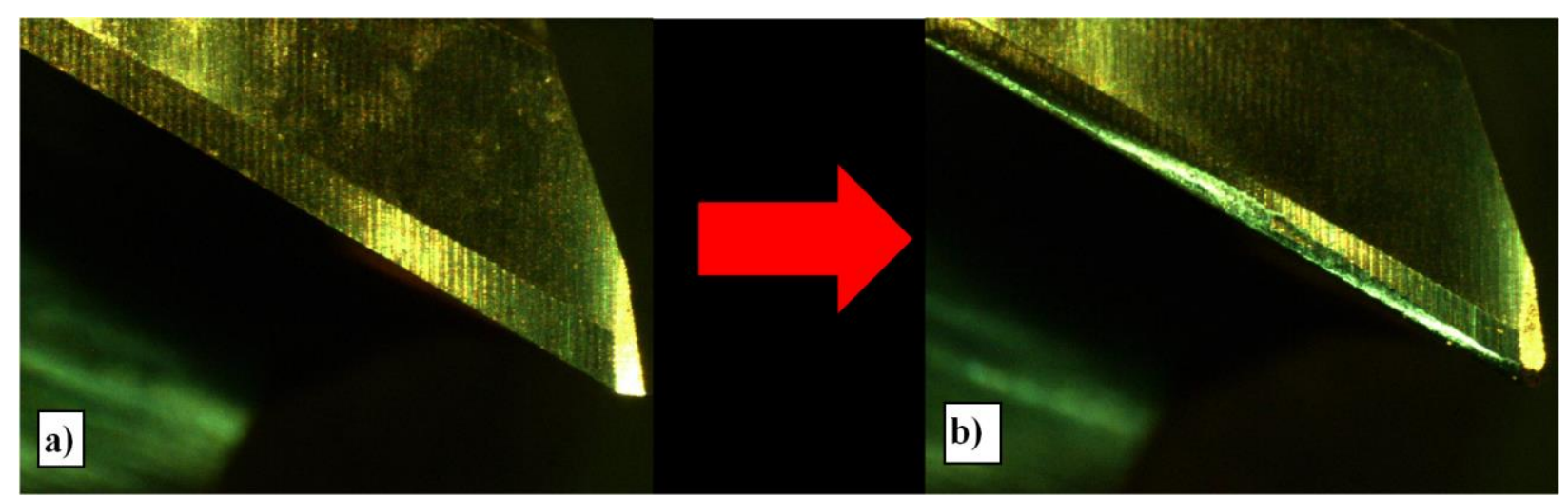

Fig. 3. Sharp cutting edge (a) and worn cutting edge (b)

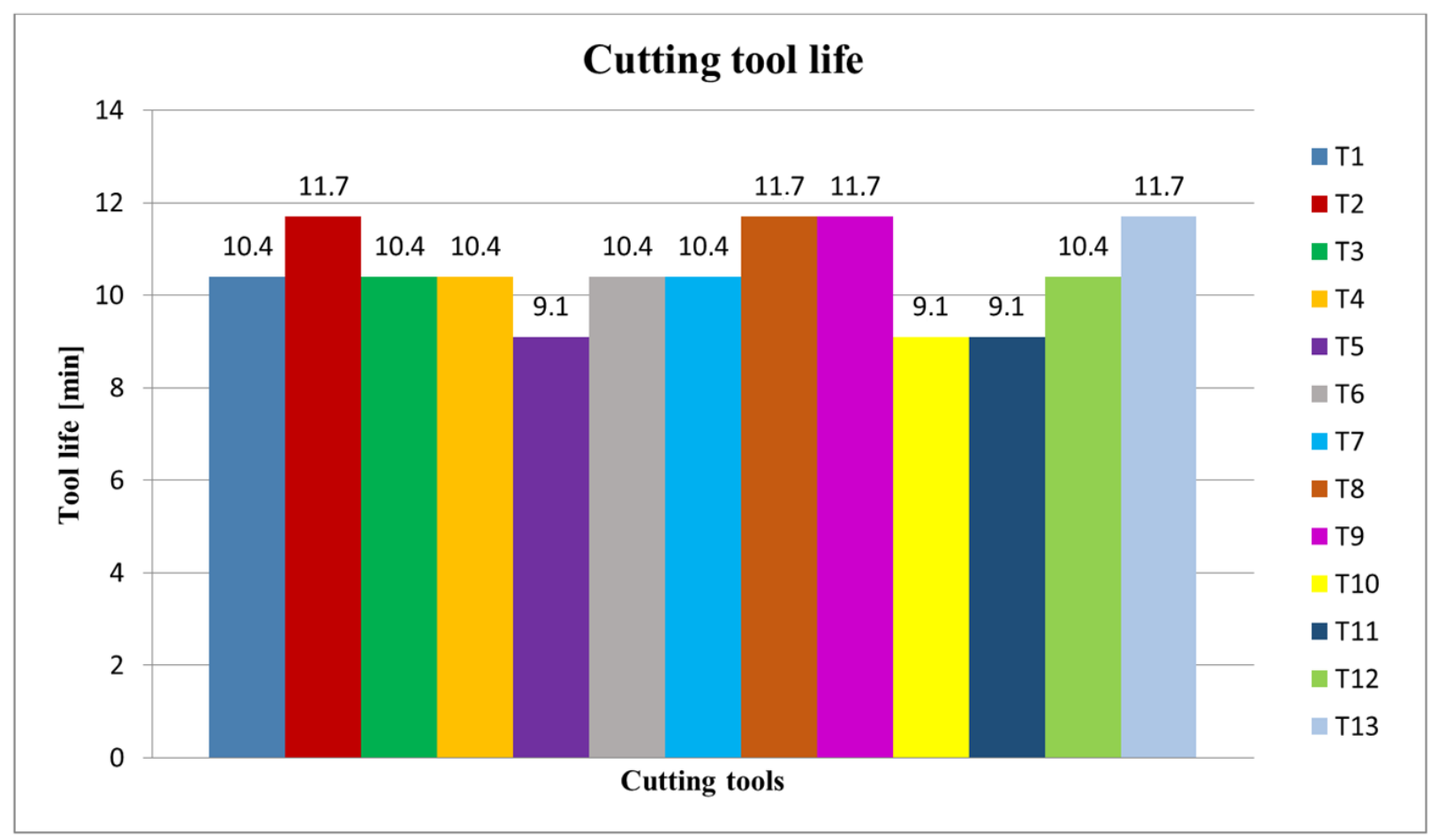

Fig. 4. Cutting tool life

Cutting forces were measured while machining Inconel 718. Measuring was carried out always during the first cut when the wear mechanism started and during the last cut when the flank wear reached the critical value $\mathrm{VB}_{\text {crit. }}$ The dominant component of the cutting force was the y-component $F_{y}$. Fig. 5 shows a summary of cutting forces $F_{y}$ during the first (Fy00) and the last (Fy150) cut of each tool. All the cutting tools show a very similar Fy150 of about $350 \mathrm{~N}$ when reaching $\mathrm{VB}_{\text {crit. }}$. This is caused by the changing of the cutting edge geometry due to the similar wear mechanism for all the tools. However, some differences between $\mathrm{CW}$ and $\mathrm{CCW}$ relief grinding strategies can be seen during the first cut. The cutting tools where the CW strategy was used reached higher values of Fy00 than cutting tools with a CCW strategy (Fig. 5).

There is also seen a difference in the force during the first impact into the material (Fig. 6). It is assumed that this impact force is due to the different quality of the cutting edge after grinding. Cutting tools ground using a CCW strategy are characterized by a sharp cutting edge which can more easily penetrate the material due to less cutting resistance. Cutting tools ground using a CW strategy are characterized by the chipping formed on the cutting edge which increases the cutting resistance. The chipping is more significant when the grinding feed rate increases. 


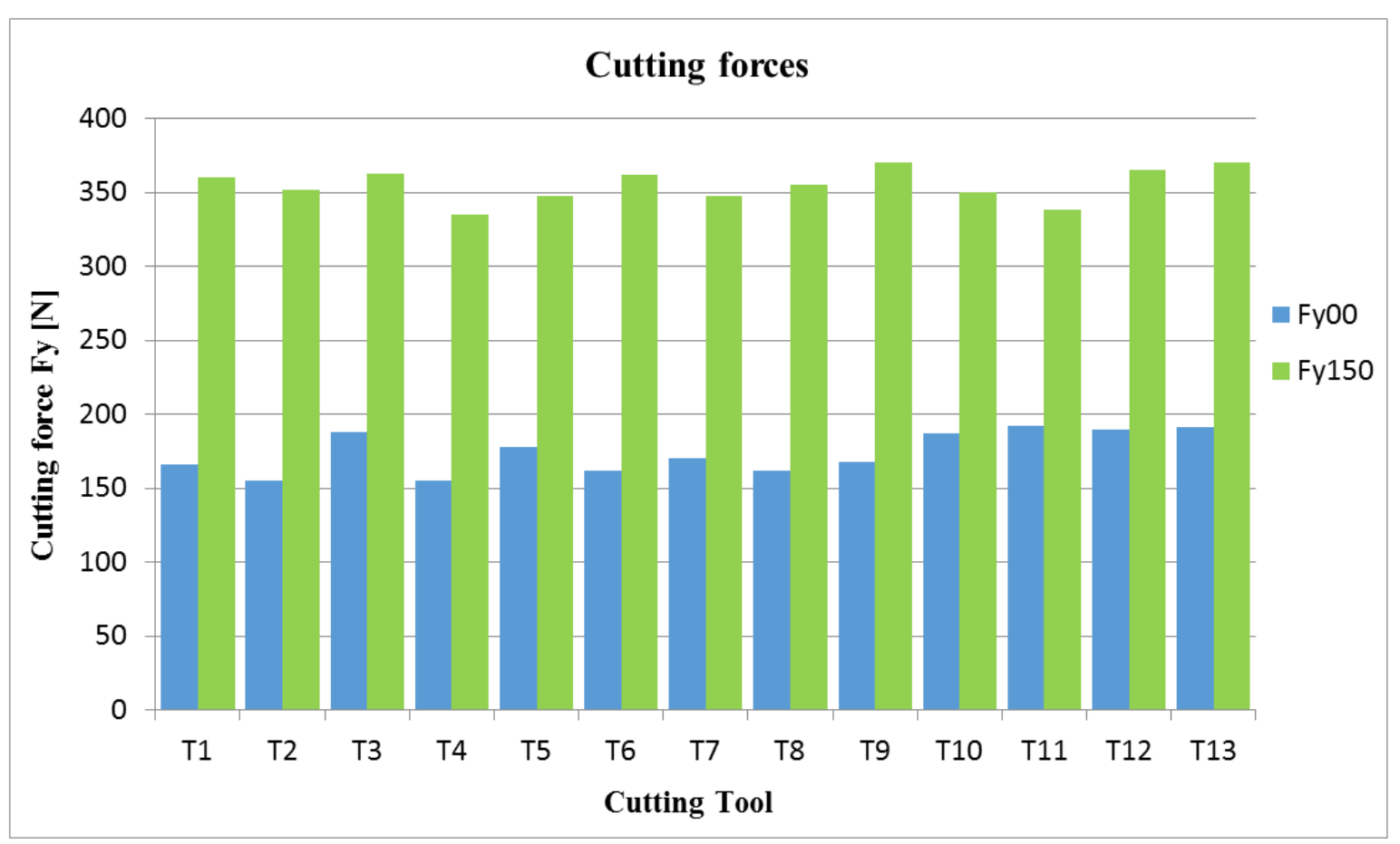

Fig. 5. Cutting force $\mathrm{F}_{\mathrm{y}}$ at the beginning and at the end of the tool life

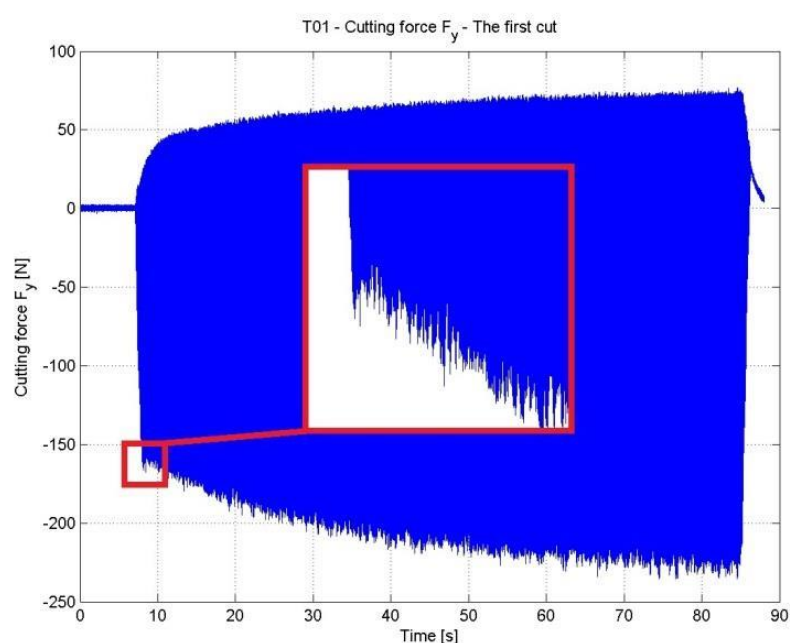

a)

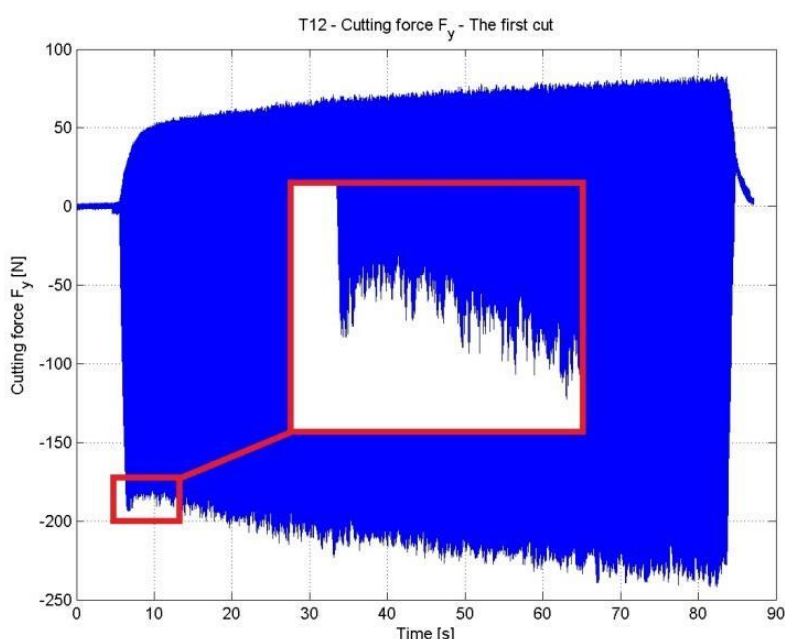

b)

Fig. 6. The impact force $\mathrm{F}_{\mathrm{y}}$ of tool T1 (a) and T12 (b)

\section{Conclusions}

Experimental milling of Inconel 718 was carried out with all cutting tools. The main aim was to determine the influence of the cutting edge quality obtained by grinding on the cutting force and cutting tool life. All cutting tools were without coating or any after-grinding edge preparation. It was found that cutting tools grinded by CCW strategy at the higher feed rate (230 to $260 \mathrm{~mm} / \mathrm{min}$ ) achieve slightly higher durability despite the worse quality of the cutting edge. The same effect occurred for tools grinded by CW strategy. Difference in the impact cutting force was found between CCW and CW strategy. Tools grinded by $\mathrm{CW}$ strategy achieved higher force Fy00 during the first impact into the material. The best results in terms of cutting tool life achieved tools T2, T8, T9, T13 with durability of 11.7 min. The worst results were achieved by tools T5, T10, T11 whit durability $9.1 \mathrm{~min}$. This experiment showed that different quality of the cutting edge after grinding has a little effect on the cutting tool life and that the worse quality of the cutting edge can achieve the same or the better results when the cutting tool without coating is used. However the worse cutting edge quality showed the higher impact force which affects the stability of the cutting process. The worse quality of the cutting edge would also affect the adhesion of the thin layer adversely when the coating is used. The results of this experiment will be used for further study where this influence on the coating will be investigated. 


\section{Acknowledgments}

The present contribution has been prepared under project LO1502 'Development of the Regional Technological Institute' under the auspices of the National Sustainability Programme I of the Ministry of Education of the Czech Republic aimed at supporting research, experimental development and innovation.

\section{References}

[1] Yin, L.; Spowage, A. C.; Ramesh, K.; Huang, H..; Pickering, J. P. \& Vancoille, E. Y. J. (2004). Influence of microstructure on ultraprecision grinding of cemented carbides. International Journal of Machine Tools \& Manufacture, Vol. 44, pp. 533-543, ISSN: 0890-6955, Elsevier.

[2] Baksa, T.; Moravek, M. \& Zetek, M. (2016). Influence of the coated carbide grade on the cutting tool life when machining Inconel 718. Key Engineering Materials, Vol. 674, pp. 271 - 276, ISSN: 1662-9795, TTP.

[3] Ucun, I.; Aslantas, K. \& Bedir, F. (2013). An experimental investigation of the effect of coating material on tool wear in micro milling of Inconel 718 super alloy. Wear, Vol. 300, pp. 8-19, ISSN: 0043-1648, Elsevier.

[4] Liao, Y. S.; Lin, H. M. \& Wang, J. H. (2008). Behaviors of end milling Inconel 718 superalloy by cemented carbide tools. Journal of Material Processing Technology, Vol. 201, pp. 460-465, ISSN: 0924-0136, Elsevier.

[5] Zetek, M.; Cesakova, I. \& Svarc, V. (2014). Increasing Cutting Tool Life when Machining Inconel 718. Procedia Engineering, Vol. 69, pp 1115-1124, ISSN: 1877-7058, Elsevier.

[6] Hadi, M. A.; Ghani, J. A.; Che Haron, C. H. \& Kasim, M. S. (2013). Comparison between up-milling and downmilling operations on tool wear in milling Inconel 718. Procedia Engineering, Vol. 68, pp. 647-653, ISSN: 18777058, Elsevier.

[7] Jawaid, A.; Koksal, S. \& Sharif, S. (2001). Cutting performance and wear characteristics of PVD coated and uncoated carbide tools in face milling Inconel 718 aerospace alloy. Journal of Material Processing Technology, Vol. 116, pp. 2-9, ISSN: 0924-0136, Elsevier.

[8] Cesakova, I.; Zetek, M. \& Svarc, V. (2014). Evaluation of Cutting Tool Parameters. Procedia Engineering, Vol. 69, pp 1105-1114, ISSN: 1877-7058, Elsevier.

[9] Schornik, V.; Zetek, M. \& Baksa, T. (2015). Durability of the cutting tool with different thin layers when Inconel 718 is machined. Proceedings of the 26th DAAAM International Symposium, pp.0678-0682, B. Katalinic (Ed.), Published by DAAAM International, ISBN 978-3-902734-07-5, ISSN 1726-9679, Vienna, Austria.

[10] Schornik, V.; Zetek, M. \& Dana, M. (2014). The influence of working environment and cutting conditions on milling nickel-based super alloys with carbide tools. Procedia Engineering, Vol. 100, pp 1262-1269, ISSN: 1877-7058, Elsevier. 